\title{
STUDENTS' NARRATIVES ON GENDER AND SEXUALITY IN THE PROJECT OF SOCIAL JUSTICE AND BELONGING IN HIGHER EDUCATION
}

\author{
S. Ngabaza* \\ e-mail: sngabaza@uwc.ac.za
}

\section{T. Shefer*}

e-mail: tshefer@uwc.ac.za

\section{Clowes*}

e-mail: Iclowes@uwc.ac.za

*Department of Women's and Gender Studies

University of the Western Cape

Cape Town, South Africa

\section{ABSTRACT}

Student protests in South Africa over the last few years have re-energized the project of social justice in higher education. While emphasis has been on decolonizing the curriculum and the university spaces, there has also been a powerful mobilization around the lived experiences of students, including sexual and gendered practices of exclusion and othering. Students' activism and a growing body of research speak to continued practices of exclusion, marginalisation and injustice, not only in the classroom, but in everyday experiences of un/belonging on the basis of intersectional raced, classed, gendered, sexualised and other forms of social identity and difference. Efforts to understand the lived experiences of young people within diverse higher educational contexts are arguably especially important in this context and this article seeks to explore such experiences with a particular focus on the entanglement of gender and sexuality with student citizenship. The article draws on research with students at the University of the Western Cape (UWC) who engaged in a participatory photovoice research project in a feminist research methodology module. Students were asked to take photos on and around campus that represented un/safe spaces for them and to write short narratives on these. In this article we apply a gendered lens to reveal the intersectional dynamics that shape students' experiences of un/belonging and un/safety on campus. The narratives and images generated by students in thinking about their sense of safety or unsafety on campus speak to a multiplicity of spaces, both symbolic and physical, that impact on experiences of belonging, either enhancing belonging or facilitating exclusion. Student narratives revealed the complex intersections between gender and sexuality in different locations, at different times, on and between campus (including, the campus bar, the sports field and commuter taxis), and how these operate in ways that validate 
heteronormative gender and sexual identities and practices, while marginalising alternative, nonconforming genders and sexualities. Taking these narratives seriously means acknowledging ways in which gender, sexual and intersectional injustices limit students' ability to participate as equal citizens in a higher education context and flags the value of student voice in the project of social justice in higher education.

Keywords: university students, narratives, belonging, citizenship, gender and sexuality, photovoice research

\section{INTRODUCTION}

Scholarship illustrates that students' experiences of campus life mirror exclusionary and unequal practices on the basis of gender, race, class, and other markers of inequality that they face in the outside world (Collins 2014; Clowes et al. 2009; Hames 2007; 2009; Gordon and Collins 2013). Material and ideological contexts of inequality, and how they are played out in higher education, remain instrumental in shaping students' participation in higher education. South African students' experiences on university campuses continue to be shaped by the inequalities and broader social perceptions of being and belonging, which find their roots in Apartheid history and centuries of colonisation. The recent spate of students' protests across the country is testimony to general frustration with the slow pace of the project of transformation and social justice in South African universities. Lived experiences continue to be significantly shaped by the legacies of apartheid and its divisive and unequal systems of education, and further bolstered by the strengthening of individualised and corporatised neoliberal policies in higher education (Badat 2010; 2016; Mbembe 2015a; 2015b).

Protests on South African campuses undeniably position students as agents of social transformation as evidenced in the "\#rhodesmustfall" movement which spread out to other institutions, mutating into other similar "hashtags" and resulting in the removal of offensive statues as well and perhaps more importantly flagging the imperative of decolonial efforts in higher education at multiple levels. The "\#feesmustfall” movement which followed with widespread protests at the end of 2015 saw no fee increment for 2016 and continues to pose significant challenges to funding constraints for the majority of students, generating efforts for more comprehensive student funding in South African higher education. While scholars like Badat (2016) and Cloete (2015), cite numerous structural and political inconsistencies and inequalities linked to the history of racial capitalism as undergirding the current wave of protests, student protests have surfaced the more nuanced, often invisible contexts of binaried social identities and normative practices relating to intersectional marginalities of gender, sexuality, age, citizenship and many others. Discursive and material practices of privilege and power on the basis of historical and current divides shape experiences of belonging and/or 
exclusion, impacting on how students experience campus life (Whitehead 2012; Ahmed 2012) and their engagement in the academic programme. Students' (un)safety on campus is central to the academic project the world over, yet students' own narratives have not been well represented in the literature. A growing body of work is emerging that documents students' experiences on campus on the basis of different emphases, including foci on violence and injury (Davis 1996; Kelly and Torres 2006; Ratti 2010; Collins 2014; Ahmed 2012; Ngabaza et al. 2015), sexuality (Bradbury et al. 2012; Hames 2012; Glassmann 2012), racialized spaces (Pattman 2007; Bhana 2014) and diversity (Shefer et al. 2017). Research that focuses on students' experiences and perspectives is arguably imperative to enhance a more robust understanding of daily challenges on campus and how these challenges inform experiences of belonging and engagement both socially and pedagogically in the academic project. A better understanding of students' diverse experiences of un/belonging are key to any efforts at social justice in higher education in South Africa.

The article is based on a group of students' experiences on one university campus in South Africa that raises a wide range of considerations related to both discursive and material factors that constrain or facilitate their sense of belonging and safety. In this respect, we consider the academic project as transcending the mainstream institutional practices in the lecture rooms to embrace consciousness of social, material and cultural dynamics that holistically produce a critically active citizenship (Zepke 2015). The project of developing critical citizenship includes attention to the multiple contexts that constrain or promote students' feelings of belonging and ensuring this is nurtured throughout all their interactions on campus (Thomas 2012). This article documents a group of students' constructions of and reported experiences of belonging and comfort and/or exclusion and marginalisation as they occupy diverse spaces on campus, both spatialy and temporarily.

\section{THE STUDY}

This article draws on narratives generated as part of a research project with both pedagogical and research goals of centering students in teaching and learning and knowledge production. The data was generated within a feminist research methodology class directed at encouraging students' participation in learning research methodological knowledge and skills by employing a photovoice participatory action research, while also producing valuable data for social justice efforts in higher education. A group of 147 third year students participating in the class were asked to identify and take photographs of places where they felt safe or unsafe on campus. The photographs were accompanied by a narrative that explained why the students felt the way they 
did in those particular spaces. Students shared their narratives with peers and worked in groups to analyze their data through a qualitative thematic approach. They also presented their work in a public exhibition which raised valuable issues resonating with both staff and students on campus. In this article, we draw on these narratives to explore the key themes emerging that speak to experiences of belonging and that inform the larger project of social justice in higher education. Drawing on a qualitative thematic analysis, also informed by discourse analysis, we followed Braun and Clarke (2006) who emphasise reading and re-reading of data, coding and identifying themes. Key themes emerging from students' photo-narratives that speak to the complexities of social and group identities as they shape experiences of belonging are presented. We attempt to illustrate the potential of such narratives for generating understanding and challenges to the complex continuities of inequality and injustice on campus, arguing the value of students' reflections in engendering the potential for change.

Standard procedures for ensuring ethical research practice were adhered to. Students were aware of and valued the fact that their narratives may inform published research and indeed were encouraged to participate in this research (see Ngabaza et. al 2013; 2015; for student authored research from this research over a number of different years). Students signed a consent form at the beginning of the course that gave permission to their data being drawn confidentially and anonymously.

\section{STUDENT NARRATIVES ON SAFETY AND BELONGING}

This article draws on photo-narratives of students that represent experiences of safety and unsafety as a way to gain access to narratives on citizenship and belonging in the university. We consider safety as including both material and affective components, whilst students' narratives foreground unsafety as anxiety or fear of potential assaults or violence, experiences of safety are also largely articulated as emotional and symbolic (Ahmed 2004; 2012). Here safety emerges as strongly resonating with a quest for belonging, acceptance, inclusion and comfort (Badat 2016). As citizens of the institution, students reflect on how continuous feelings of being marginalized in particular spaces on campus are both disabling and prohibitive in their academic project. Citizenship is a very broad spectrum that has been theorized and analysed by numerous scholars (see Waghid 2010; Constandius and Bitzer 2015; Keet and Carolissen 2010; Carolissen 2012). This article is underpinned by an understanding of citizenship as "pertaining to participation and exclusion" (Stevenson et al. 2015, 1), as we strive to understand how different student groups occupy spaces on campus and how such occupation enables or disables their participation in the academic project. We however acknowledge that such a conception of 
citizenship is limited, considering the broad spectrum in which citizenship is theorized, understood and contested in the social sciences.

Students' narratives of (un)safety speak poignantly to narratives of belonging. These narratives are circumscribed within a vocabulary of social identity within both campus and larger social context, and as Carolissen $(2012,635)$ argues identity narratives "always relate to belonging”. Perhaps we should also emphasize the complexity of unpacking narratives of belonging as such narratives are always mediated by numerous intersectional factors, as this article will also show. In the same manner, students' feelings of (un)safety are constructed on “multiplex axes of difference” (Yuval-Davis 2006, 200) and sameness as students attempt to maintain certain boundaries they identify with as well as challenge, subvert or resist those they struggle to identify with or find discomforting. Fuvell (1999, cited in Yuval-Davis 2016, 368) sees and defines this process as "politics of belonging; the dirty work of boundary maintenance”. Yet maintaining these boundaries is also marked by struggles that determine, entitle and inform dimensions of participation for the community members (Yuval-Davis 2016). We unpack such narratives showing how students contest particular spaces, embrace some, and also challenge others as they clamour for what may be seen as full academic citizenship.

Numerous factors such as gender, race, class, religion, citizenship, sexuality, time of day etc. emerged in student narratives as different positionalities from which students contest belonging. Since the study raised a wide range of experiences that speak to experiences of belonging, we have chosen here to focus particularly on narratives foregrounding intersectional identities through the lens of gender, sexuality and academic citizenship, showing how occupying certain spaces by particular students evoke inclusionary and exclusionary feelings. Further the article underscores the potential value for such narratives to transform spaces indicated as inhibitive to enabling places for academic participation.

\section{INTERSECTIONAL GENDER AS INCLUSIONARY AND EXCLUSIONARY}

Numerous students found gender powerfully framing the participation or occupation of certain spaces by male or female students especially at particular times of the day. One such space was the university bar, popularly known as "the barn". The barn was described as a hypermasculinized and potentially violent space, which was very intimidating particularly to female students who felt uncomfortable from sexual gestures from the male patrons who were in most cases their fellow students (see also, Clowes et al. 2009; Shefer et al. 2012a; 2012b)

“This space is unsafe for me as my fellow male students frequent this place often to drink and with 
often the intent to pick-up girls for a one night stand. This space for me as a young female is unsafe as often guys will cat-call women, pressure women to go home with them, get women drunk in order to go home with them, there is a possibility of my drink getting spiked, also having the personal space and body violated by inappropriate touching from the males, the possibility of drunken violence being inflicted on me.” (bf) ${ }^{1}$.

"The Barn is often filled with male students and alcohol can make men lose some of their inhibition, they are not in complete control when they are drunk and so the comments that they make towards me or when they whistle or wink at me makes me feel uncomfortable. I experience anxiety when I walk past The Barn because I am aware of fights that have occurred when men get drunk.” (wf).

"So although this space is filled with diverse people and is a social, vibrant place where students can chill and de-stress together, it is unsafe for me as I always have to be alert and aware of what is happening around me. I also feel uncomfortable at the same time because of the perceptions from the males and sometimes also the women that if you frequent a place such as the Barn you might be easy, and looking for guys to take you home with him, which leaves me feeling like ... being judged by fellow students about your morals, religious beliefs and what kind of person you are. If I were a male I would feel much safe in this space as I would be less likely to get sexually harassed or have my drink spiked.” (bf).

The narratives emphasize how gender intersects with other factors such as heteronormative sexuality to inform contests of belonging and exclusion in the student pub. A female student's presence in the campus bar is contested, rendered against stereotypes receptive to a particular kind of "woman", a woman who is perceived by both male and female students as "available" and “immoral". This, well documented whore-madonna discourse (see Shefer 2009), legitimises moral judgements and the threat of violation. Of particular concern is the discomfort expressed by female patrons who feel physically threatened and also objectified by the "male gaze” that renders them sexual objects rather than peers deserving of mutual respect. Whilst most female students expressed negative feelings about the barn as generally exclusionary to female patrons, it was interesting to note that some female students thought it was a more welcoming space as compared to visiting other popular bars in Long Street, that is, off campus in the City Centre. Possibly linked to the geographies of space, with the city centre a space historically white and middle class and also relatively far from this campus, requiring a safe means of transport, the location of a campus bar then becomes a comfort and safe space relative to these other more public spaces represented as dangerous and unsecuritized:

"Now this is my happy place and for many, I feel safe at the Barn during the day and even during the night, because it's one of my special places, where I can go drink knowing that I can just walk to my room, unlike Long street having to look for a cab or getting robbed whilst miles away from residence. The other reason why I feel safe at the barn is because ... students are searched for dangerous weapons before they enter the Barn and there are bouncers all over the barn who are always looking out for us ....” (bf). 
Gendered experiences of mobility to and from campuses, obviously intersecting with class inequality, were also evident in students' narratives particularly related to fear of sexual violence when using public transport to and from campus. Making use of the commuter buses to and from campus and trains are the primary mode of transport for many students, therefore shaping their daily experiences in accessing campus. Occupying these taxis or taking the train, evoked anxiety and discomfort among mostly female students who feared sexual assault as expressed in the following extracts:

"This is a picture of the minibus I take to the campus of UWC. During daytime and when the minibus is crowded I feel much safer in a minibus than when I am taking the train for example where I have experienced people being more intimidating. In the daytime, I do not feel vulnerable in the same way as after it gets dark. This is because the minibuses are crowded and being among people makes me feel less vulnerable, considering that the risk of being victimized is lesser.” (bf).

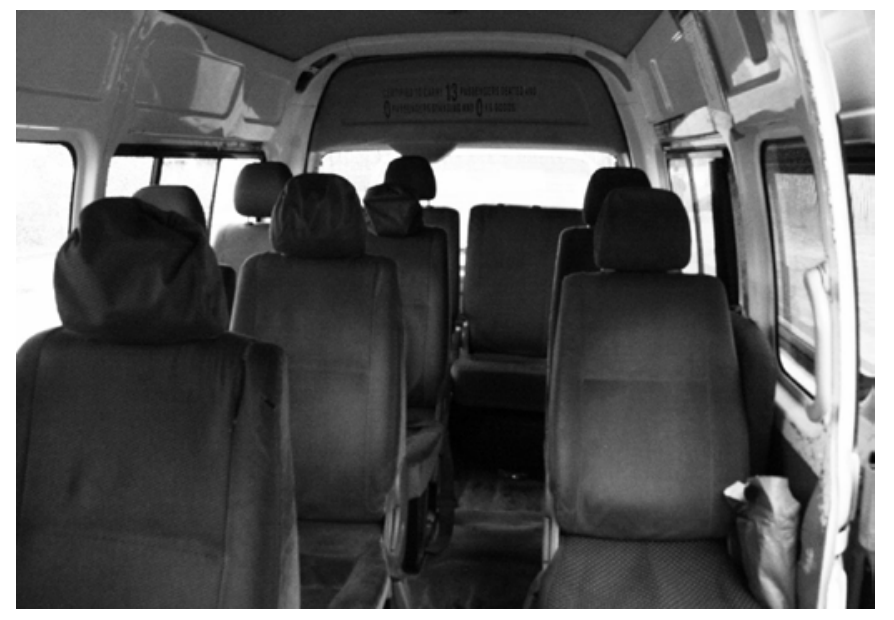

"This is a picture of the minibus I take to campus. The transport to campus is a big part of my daily life, as I live quite far away from campus. Whether I perceive this place as safe or not depends on several external factors such as what time it is, if I am alone, and also the appearance of the driver. I am trying to avoid empty minibuses because of the stories I have heard about people being robbed or sexually assaulted by the driver and dumped somewhere in the outskirts.” (wf).

"My fear of being sexually assaulted or even raped is much greater and almost constantly present in a situation when I am in a situation where it is hard to escape, such as in a minibus. I believe that my experience with the minibus as an unsafe place is most of all shaped by my biological gender. Considering the statistics of sexual victimization and rape of women in general and particularly in Cape Town, I know I am a lot more vulnerable as a woman.” (wf).

These narratives foreground the challenge and fear of sexual assault in this context and space. Students did however note that this is not a campus challenge but an issue of concern in the wider society, well articulated in Gqola's (2015) recent important contribution to understanding "rape culture” in South Africa. Sexual violence against women and the threat thereof is deeply entangled within intersecting power relations (Yuval-Davis 2010) and it is not surprising that one student 
emphasizes "where it is hard to escape, such as in a minibus", showing how the space robs her of power, rendering her "vulnerable” and defenceless. Fear of sexual assault on campus is real for numerous female students around South African universities, see for example (Gordon and Collins 2013; Ngabaza et al. 2015; Hames 2012; Bradbury et al. 2012; Dosekun 2007). For these female students, living in perpetual fear of assault is a matter of great concern; it means being extra vigilant on a daily basis, of constant cautionary self-regulation and discipline, undermining their ability to "belong” to the academic project.

\section{SEXUALITY, INCLUSION AND MARGINALISATION}

Students' narratives flagged the way in which non-normative masculinities and femininities and sexual practices outside of heterosexuality remain othered and stigmatized on campus and powerfully undermine experiences of belonging for some students. Men subscribing to dominant forms of masculinity with emphasis on successful heterosexuality appeared to be particularly resistant to subverting this norm, thus having a purchase on belonging while marginalising others in particular spaces on campus. Once again the barn continued to be represented by students as a place of contestation, a site of dominance and marginalisation. Some students challenged the exclusionary tendencies of the barn.

“... everybody is entitled to their own sexuality, when I say this I am referring to the Lesbians, Gay, Bi-sexual, Transgender, Intersex and Queer (LGBTIAQ+) Community ... previous experiences and research has shown that a lot of people who are from different ethnic groups as well as different ages who go to the Barn to enjoy the nightlife on campus have been prejudiced and discriminated against (the LGBTIAQ+) on the basis of who they are.” $(\mathrm{cm})$.

“... there was a situation where the gays had to set up a petition regarding the use of the restrooms facilities (toilets) of the Barn because a few heterosexual men felt uncomfortable to use these facilities with gays.” (bf).

Students identifying as LGBTIQ+ found spaces like the Barn, defined as heterosexual and predominantly male, not only exclusionary but also threatening, unsafe and potentially violent. Yet, their resistance and defiance is also evident since this group of students illustrated their agency by successfully petitioning for inclusion in terms of access to the bar restrooms. Further, students identifying as LGBTIQ+ were understood to be marginalised - as not belonging, in narratives on participation in the university's rugby team. The following extract emphasises the dominance of rugby as simultaneously a masculine sport and a symbolic tool to "bully", shame and silence "non conforming masculinities". Of concern though are the emotional scars of exclusion that the students emphasise. Such narratives flag the dominance of hegemonic masculinity (Connell 1987; 1995), a concept within critical masculinities studies which has 
been widely taken up in the South African gender justice literature (Morrell, Jewkes and Lindegger 2012). Refering to the dominant or idealised form of masculinity or "ruling masculinity” (Ratele 2006), and certainly not uncontested (Ratele 2008), in South Africa as in many other parts of the world, such masculinities reportedly hinge around sexual prowess, male control in households and public terrains, and a physically and symbolically macho identity (see Ratele 2008; Walker 2005). Importantly, while student narratives flagging hegemonic masculinity and how it serves to "other" and exclude non-conforming genders and sexualities from fully participating in campus activities, they are also voices advocating for transformation in these spaces:

"From personal experience and similar stories shared by my peers, encounters have emerged where the rugby field has become a space of bullying. Especially amongst the male sport participants, being heterosexual is almost as important to practice a sport as it is to know the rules of that particular sport.” (cm).

"The verbal abuse often comes at a price of losing hope, interest or the determination of being a rugby player in a heterosexual dominated space. One might think that physical abuse is worse than verbal abuse, however, wounds heal. It is the long term psychological effects of continuous verbal abuse that has a deeper and lasting effect on an LGBTI member trying to be a rugby player.” $(\mathrm{cm})$.

"The rugby field should be a safe space to practice a sport which has been part of our heritage and history, however, society and possibly even the sport code itself has made rugby into a heterosexual sport. If you do not possess certain masculine characteristics and tendencies, the rugby field is definitely not a safe space for you.” (cm).

Occupying minibuses to and from campus was also flagged as a potential for exclusion, shaming and attack of students who practice non-heteronormativity. This feeling of stigma is complicated by the students' reference to the potential attackers as belonging to their student community.

\footnotetext{
"Since the taxi ride is often of a short duration, an impromptu debate on sexual identity or orientation generally prompts all passengers to voice their opinion. These opinions are often not thought through and end up being hateful and offensive mockery aimed at the homosexual or bisexual individuals."

"It feels unsafe to be that individual in a taxi ... as one can end up being physically, psychologically and morally attacked by the same members of a community which one considers being part of." $(\mathrm{cm})$.
}

Not all spaces were hostile to students identifying with non-normative genders and sexualities as evidenced in the following extract. Here students foreground the inclusive nature of the gender neutral bathroom in one of the hostels, describing this as "advancement in gender equality”, the student feels that such endeavours by the institution indeed promote inclusiveness 
and an element of sexual privacy and freedom, which is clearly of value, especially in the light of the earlier example where a group of students had to petition for the right to access male bathroom facilities in the student pub. Such an example raises possibilities for transforming hostile and exclusionary spaces to accommodate diverse gender and sexual identities.

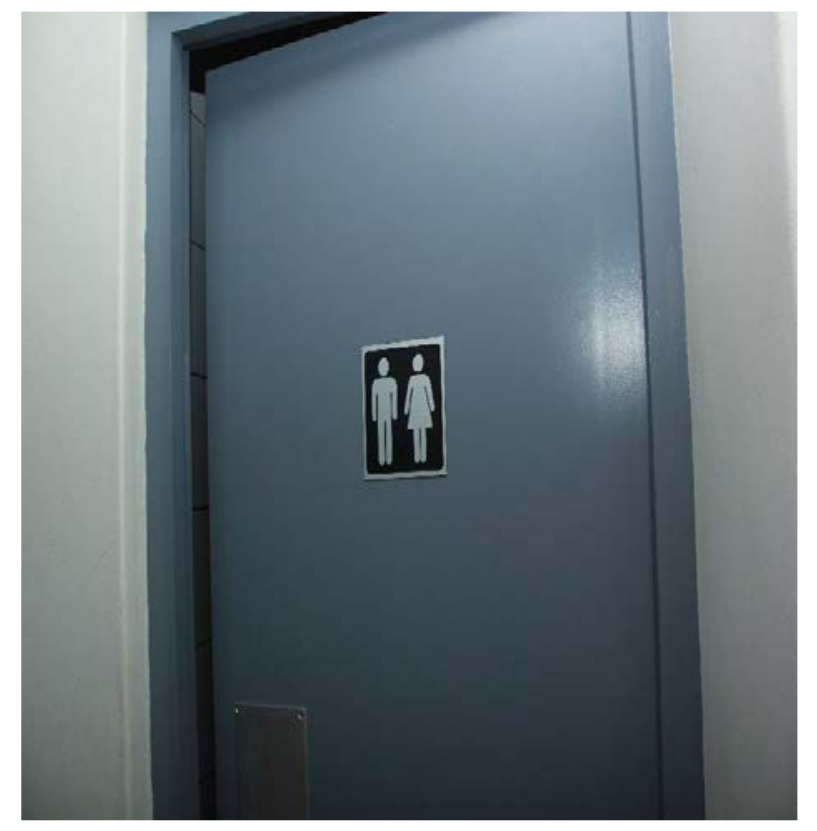

"This is a picture of the ablution facilities within a dormitory on campus. The symbol on the door not only makes me as a gay man feel welcome, but also reminds me that as men and women, we are similar in so many ways. Although many straight students, both male and female feel that these facilities should be kept apart, those of other sexualities do not necessarily feel that this is an issue. I personally feel safe within these premises at all times of the day as it blurs the line between being a man or a woman.”

"I would not need to be scared of being mocked by men for being in the 'wrong' toilet. Horrifying stories have surfaced before of males being attacked in a male only toilet facility for appearing -, or just acting too effeminate. Seeing advancements in gender equality like this brings to mind the sense that as a human race, we are slowly breaking down the social constructs of differentiation ... between man and women, gay or straight, religious or A-religious. I feel proud to be able to embrace such evolution. It feels welcoming to realise that institutions are recognising such a need and accommodating everyone from all walks of life.” $(\mathrm{cm})$.

\section{BELONGING AND ACADEMIC CITIZENSHIP}

While, as discussed above, students identified moments and spaces in which they felt unsafe, they also identified spaces accommodating of difference and receptive in ways that made them feel accepted as belonging to the academic project. These spaces were presented as welcoming and appreciative to a variety of differences, including on the basis of sexuality, gender, race, class, geographical background, citizenship, and others among the student body, as emphasized in the following extracts. Here students found unity in purpose and shared common values in diversity clearly indicating campus 
citizenship, as a “core membership” within “multiple memberships” (Carolissen 2012, 632).

"The student centre is place where you can grab something to eat and catch up with friends. It is where you have fun and study at the same time. It is the loudest place on campus. In the student centre, I have never been treated differently just because of the fact that I am a black female student from a small town in the Eastern Cape. In my three years of being a student ..., I have only experienced a warm welcoming environment in the student centre. This is evident especially when there is an event at the student centre, males, females, Coloureds, Indians, Blacks and Whites come together and have fun.” (bf).

Similar remarks were made when students narrated their experiences in lecture halls, once again emphasizing the commonalities within acknowledged differences.

“... one of my lecture halls, ... is a place at campus I perceive as safe. ... I believe I feel safe in a lecture because I am in a room with other students, a group I belong to, even though I am an exchange student and do not know the other students very well. A group of students can be very diverse when it comes to gender, religion, background and attitudes, which can make the interaction across groups complicated and sometimes uncomfortable. However, when I am at a lecture, I get the impression that we are all, first of all students, and the sense of anonymity creates a safe environment.” (wf).

"Lecturers are very much in control and do their best to cultivate respect that will benefit everyone in that room. One needs to respect one another irrespective of gender, race, and sexual preferences. The treatment is the same towards lecturers and among students themselves. The environment does not allow people to behave or see themselves as different from others not even better than others or anyone to be bullied. Students would seat next to one another speak and laugh together no matter who they are. Students might come from different races, might have different sexual identities or even different genders but we all belong to one group in the lecture room.” (bm).

"People learn to socialize together as different as they might be, because in the case where you need something you are bound to speak to the person next to you as you cannot go around and look for people you associate yourself with so you are bound to associate yourself with the person next to you. Another reason that makes a class a safe place is that there is group work that most make students to become close to one another laughing and chatting while discussing within the group and that brings about closeness. This place is safe for me because everyone treats one another with respect and we all become one.” (cf).

These extracts indicate what different spaces mean to students in different contexts and also indicate possibilities of transforming unreceptive spaces to mutually inclusive ones in ways that will encourage openness to difference and inclusivity in all spaces for all students for academic citizenship.

\section{DISCUSSION}

The narratives and images generated by students in this research speak to a multiplicity of spaces, both symbolic and physical, that impact on experiences of safety and belonging, either 
enhancing belonging or facilitating exclusion through the articulation of othering and antagonism towards certain groups and categorizations on campus. In their narratives students repeatedly drew attention to ways in which gender intersected with sexuality to marginalise and exclude in ways that made them feel they did not belong in particular spaces. This article thus focused on narratives illustrating some of the complex intersections between gender and sexuality in three locations - the campus bar, the sports field and commuter taxis - and how in operating in ways that validate heterosexual masculinities, femininities and non conforming masculinities are simultaneously marginalised. Taking these narratives seriously means acknowledging ways in which gender, sexual and intersectional injustices limit students' ability to participate as equal citizens on this campus - as well as in society more generally. Students anxieties about the possibility of physical, emotional or psychic violence are, as substantial research has shown, rooted in social contexts in which such violence is widespread and common place. The heterosexism and homophobia that underpins the widespread gender based violence and sexual harassment of female and non conforming male students is a serious concern across all South African universities, (see for example, Bennet 2005; Bennett et al. 2007; Hames 2007; Jagessar and Msibi 2015). Heteronormative practices that are "discomforting, alienating and disempowering” (Badat 2016, 10) continue to undermine campus citizenship as a liberating project, despite national legislative instruments such as the Gender Equality Bill. Although legislation provides potential for transformation for women and other previously marginalised categories, our research suggests that strategies for transformation need to do more than simply provide legislative frameworks. As Badat (2016) suggests, marginalised groups have largely been expected to assimilate into unwelcoming institutional cultures, to accept and tolerate stigma and continued forms of marginalisation as the price of entry (Badat 2016). A campus in which students are able to feel they belong requires us to find ways to challenge and stigmatise hetero patriarchal modes of thinking and cultures in institutions of higher learning (Loots and Walker 2015; Tabensky and Matthews 2015).

Our research also suggests that challenges to heteropatriarchal normativity do exist with students identifying facilities such as gender neutral restrooms as spaces demonstrating that they belonged. In addition, although contestations around who belonged and who did not were immanent in masculinized spaces, students also foregrounded spaces such as the student centre and lecture halls which they experienced as spaces where they belonged. Here diversity was celebrated as students found meaning beyond their "political communities of belonging" (Yuval-Davis 2016, 368), as they forged new dynamics of belonging that are characterised by inclusivity (see also Shefer et al. 2017). In this case, political categories were dismantled as students converged as equal citizens to work on their academic projects. The existence of spaces 
in which collective identities are able to emerge demonstrates that stigma and marginalisation can be challenged. It should be noted, however that it is the responsibility of all university stakeholders to work towards challenging patriarchal discourses and practices as they intersect with forms of inequality that continue to be implicated in unsafety and violence against women and other subjugated groups. Care needs to be taken that policing of spaces in ways that reproduce and legitimize exclusion and othering of some students is avoided. Academic citizenship is not simply about participation in lectures but about the occupation of all spaces accessible to students, on campus, without fear or anxiety. Everyone on campus has a role to play in contributing to an institution to which everyone feels they belong.

\section{NOTE}

1. For purposes of identification students will be referred to as black, male (bm); black female (bf); white female (wf); colored male (cm) and colored female (cf). Whilst we are aware that identifying students through such apartheid categories risks repeating and re-inscribing racist ideology, since they remain salient for the purposes of redress and continue to hold social and material meaning in contemporary South Africa we use them to enable greater understanding of the current sociopolitical location of the respondents.

\section{REFERENCES}

Ahmed, S. 2004. The cultural politics of emotion. New York: Routledge.

Ahmed, S. 2012. On being included. Racism and diversity in institutional life. Durham: Duke University Press.

Badat, S. 2010. The challenges of transformation in higher education and training institutions in South Africa. Development Bank of Southern Africa 8: 1-37.

Badat, S. 2016. Deciphering the meanings, and explaining the South African Higher education student protests of 2015-2016. https://mellon.org/resources/shared-experiences-blog/south-africaprotests/ (Accessed 30 June 2016).

Bennett, J. 2005. Research on the implementation of policies against sexual harassment in Southern Africa higher education. In Killing a virus with stones? Research on the implementation of policies against sexual harassment in Southern African higher education, ed. J. Bennett. Cape Town: African Gender Institute.

Bennett, J., A. Gouws, A. Kritzinger, M. Hames and C. Tidimane. 2007. Gender is over: Researching the implementation of sexual harassment policies in Southern African higher education Feminist Africa 8: 83-104.

Bhana, D. 2014. Race matters and the emergence of class: Views from selected South African university students. South African Journal of Higher Education 28(2): 355-367.

Bradbury, J., P. Kiguwa, A. Khumalo, M. Matlala, H. Mchunu, D. Mogopudi and Z. Ngubeni. 2012. Thinking women's worlds. Feminist Africa 17: 28-47.

Braun, V. and V. Clarke. 2006. Using thematic analysis in psychology. Qualitative Research in Psychology 3: 77-101.

Carolissen, R. 2012. Belonging: As a theoretical framework for the study of psychology and globalisation. Journal of Social Issues 68: 630-642.

Cloete, N. 2015. The flawed ideology of "free higher education". University World News, No. 389, 6 November. http://www.universityworldnews.com/article.php?story=20151104111825416 
Clowes, L., T. Shefer, E. Fouten, T. Vergnani and J. Jacobs. 2009. Coercive sexual practices and genderbased violence on a university campus. Agenda 23(80): 22-32.

Collins, A. 2014. Faceless bureaucracy? The challenges of gender-based violence and practices of care in higher education. In Care in context: Transnational gender perspectives, ed. V. Reddy, S. Meyer, T. Shefer and T. Meyiwa, 282-304. Cape Town: HSRC Press.

Constandius, E. and E. Bitzer. 2015. Engaging higher education curricula: A critical citizenship education perspective. Stellenbosch: SUN Press.

Connell, R. 1987. Gender and power. Sydney, Australia: Allen and Unwin.

Cornell, R. 1995. Masculinities. Cambridge, UK: Polity Press.

Davis, W. 1996. Educational intervention: A prescription for violence prevention at historically black colleges and universities. Journal of Negro Education 65(4): 454-461.

Dosekun, S. 2007. "We live in fear, we feel very unsafe": Imagining and fearing rape in South Africa. Agenda 21(74): 89-99.

Glassmann, D. 2012. Queer(ing) spaces: A critical analysis of physical and virtual safe spaces for lesbian, gay and bisexual college students. Georgia: University of Central Arkansas.

Gordon, S. and A. Collins. 2013. "We face rape, we face all things": Understandings of gender-based violence amongst female students at a South African university. African Safety Promotion Journal 11(2): 93-106.

Gqola, P. D. 2015. Rape: A South African nightmare. Auckland Park: MFBooks/Jacana.

Hames, M. 2007. Sexual identity and transformation at a South African university. Social Dynamics 33(1): 52-77.

Hames, M. 2009. "Let us burn the house down!” Violence against women in the higher education environment. Agenda 23(80): 42-46.

Hames, M. 2012. Embodying the learning space: Is it okay if I bring my sexuality to class? Feminist Africa 17: 62-81

Jagessar, V. and T. Msibi. 2015. It's not that bad: Homophobia in the residences of a university in KwaZulu-Natal, Durban, South Africa. Agenda 29(1): 63-73.

Keet, A. and R. Carolissen. 2010. Rethinking citizenship and social justice in higher education (editorial). Perspectives in Education 29(3): 147-149.

Kelly, B. T. and A. Torres. 2006. Campus safety: Perceptions and experiences of women students. Journal of College Student Development 47(1): 20-36.

Loots, S. and M. Walker. 2015. Shaping a gender equality policy in higher education: Which human capabilities matter? Gender and Education 27(4): 361-375.

Mbembe, A. 2015a. Decolonizing knowledge and the question of the archive. WiSER Wits Institute for Social and Economic Research, 1 May 2016. http://wiser.wits.ac.za/system/files/Achille\% 20Mbembe\%20-\%20Decolonizing\%20Knowledge\%20and\%20the\%20Question\%20of\%20the\% 20Archive.pdf

Mbembe, A. 2015b. On the state of South African political life. http://africasacountry.com/ 2015/09/achille-mbembe-on-the-state-of-south-african-politics/

Morrell, R., R. Jewkes and G. Lindegger. 2012. Hegemonic masculinity/masculinities in South Africa culture, power, and gender politics. Men and Masculinities 15: 11-30.

Ngabaza, S., E. Bojarczuk, M. P. Masuku and R. Roelfse. 2015. Empowering young people in advocacy for transformation: A photovoice exploration of safe and unsafe spaces on a university campus. African Safety Promotion Journal 13(1): 30-48.

Ngabaza, S., D. Daniels, O. Frank and R. Maluleke 2013. Contestations of the meaning of love and gender in a university students' discussion. Agenda 96(27): 128-136.

Pattman, R. 2007. Student identities and researching these in a newly racially merged university in South Africa. Race, Ethnicity and Education 10(4): 473-402. 
Ratele, K. 2006. Ruling masculinity and sexuality. Feminist Africa 6: 48-64

Ratele, K., 2008. Analysing males in Africa: Certain useful elements in considering ruling masculinities. African and Asian Studies 7(4): 515-536.

Ratti, C. 2010. Students' perceptions of campus safety at the University of Mary Washington. Fredericksburg: University of Mary Washington.

Shefer, T. 2009. Ethical leadership in and through gender and sexuality: Deconstructing heterosex in contemporary South African contexts. In Ethical leadership in and through a morally transformed society in the Western Cape, ed. G. Dames, 61-79. Stellenbosch: Sun Media.

Shefer, T., A. Strebel, S. Ngabaza and L. Clowes, 2017. Student narratives on social identities and diversity at a South African university. South African Journal of Psychology 48(1): 61-72.

Shefer, T., C. Clowes and T. Vergnani. 2012a. Narratives of transactional sex on a university campus. Culture, Health \& Sexuality: An International Journal for Research, Intervention and Care 14(4): 435-447.

Shefer, T., A. Strebel and J. J. Jacobs. 2012b. AIDS fatigue and students' talk about HIV risk. African Journal of AIDS Research 11(2): 113-121.

Stevenson, C., J. Dixon, N. Hopkins and R. Luyt. 2015. The social psychology of citizenship, participation and social exclusion: Introduction to the special thematic section. Journal of Social and Political Psychology 3(2): 1-19.

Tabensky, P. A. and S. Matthews. 2015. Being at home: Race, institutional culture and transformation at South African higher education institutions. Durban: UKZN Books.

Thomas, L. 2012. Building student engagement and belonging in higher education at a time of change: Final report from the what works project? Student Retention and Success Programme. Paul Hamlyn Foundation, Higher Education Funding Council for England, the Higher Education Academy and Action on Access. http://www.heacademy.ac.uk/resources/detail/what-worksstudent-retention/What_works_summary_report

Waghid, Y. 2010. Education, democracy and citizenship revisited: Pedagogical encounters. Stellenbosch: SUN Media.

Walker, L. 2005. Men behaving differently: South African men since 1994. Culture, Health \& Sexuality 7(3): 225-238.

Whitehead, K. 2012. Racial categories as resources and constraints in everyday interactions: Implications for racialism and non-racialism in post-apartheid South Africa. Ethnic and Racial Studies 35(7): 1248-1265.

Yuval-Davis, N. 2006. Belonging and the politics of belonging. Patterns of Prejudice 40(3): 197-214.

Yuval-Davis, N. 2010. Theorizing identity: Beyond the "us" and "them" dichotomy. Patterns of Prejudice 44(3): 261-280.

Yuval-Davis, N. 2016. Power, intersectionality and the politics of belonging. In The Palgrave handbook of gender and development, ed. W. Harcourt, 367-381.

Zepke, N. 2015. Student engagement research: Thinking beyond the mainstream. Higher Education Research \& Development 34(6): 1311-1323. 